FEATURED CASE REPORT

\title{
Instructive ECG series in massive bilateral pulmonary embolism
}

\author{
A S H Cheng, A Money-Kyrle
}

Heart 2005;91:860-862. doi: 10.1136/hrt.2004.049114

The ECG is abnormal in over $70 \%$ of patients with pulmonary embolism. Certain ECG abnormalities have been observed to return to normal after treatment. This case report describes an instructive ECG series in a patient with massive bilateral pulmonary embolism as shown by spiral computed tomography. The initial ECG showed sinus tachycardia with $\mathrm{P}$ pulmonale, although atrial tachycardia could not definitively be excluded. The patient had an increased troponin I concentration and echocardiographic evidence of right ventricular dysfunction and underwent thrombolysis with alteplase and anticoagulation with warfarin. $P$ wave amplitude gradually decreased throughout admission and her tachycardia resolved. This may reflect a reduction in right atrial strain after treatment. This phenomenon has apparently not been described in this setting. The significance of ECG changes and the role of thrombolysis in pulmonary embolism are briefly discussed.

A 61 year old retired nurse was referred by her general practitioner to the casualty department with breathlessness and central chest tightness, which was pleuritic and not associated with palpitations or autonomic symptoms. She had no cough or haemoptysis. For the preceding nine months she had also noted a swollen, tender left leg, in which she was known to have varicose veins. She took hormone replacement therapy (HRT) for post-menopausal symptoms. She had no other risk factors for venous thromboembolism or ischaemic heart disease. The patient was ambulant and independent with respect to activities of daily living. She was a non-smoker and only occasionally drank alcohol.

On examination, her temperature was $37.8^{\circ} \mathrm{C}$. Heart rate was 140 beats/min, and blood pressure was 140/80 mm Hg. Jugular venous pressure was not reported to be increased. Heart sounds were normal. Arterial blood gases on air were within normal limits, with oxygen saturation of $99 \%$ on air. Her respiratory rate was 16 respirations/min. Her chest was clear to auscultation. There was bilateral pitting oedema, more so in the left leg, in which there was evidence of varicose veins. The left leg was not tender to palpation and was not erythematous. The chest radiograph and other examination were unremarkable.

Blood results were as follows: haemoglobin $8.25 \mathrm{mmol} / \mathrm{l}$, white cell count $3.6 \times 10^{9} / \mathrm{l}$, platelets $266 \times 10^{9} / \mathrm{l}$, C reactive protein $20.1 \mathrm{mg} / \mathrm{l}$; sodium $134 \mathrm{mmol} / \mathrm{l}$, potassium $4.2 \mathrm{mmol} /$ $\mathrm{l}$, urea $4.9 \mathrm{mmol} / \mathrm{l}$, creatinine $73 \mu \mathrm{mol} / \mathrm{l}$; albumin $36 \mathrm{~g} / \mathrm{l}$, total protein $68 \mathrm{~g} / \mathrm{l}$, alkaline phosphatase $108 \mathrm{IU} / \mathrm{l}$, bilirubin $3 \mu \mathrm{mol} / \mathrm{l}$, alanine transaminase $113 \mathrm{IU} / \mathrm{l}$; thyroid stimulating hormone $31 \mathrm{mIU} / \mathrm{l}$; and free thyroxine $11.7 \mathrm{pmol} / \mathrm{l}$.

A screening echocardiogram showed a dilated hypokinetic right ventricle. A working diagnosis of pulmonary embolism (PE) was made. Subcutaneous enoxaparin and analgesia were administered, and antiembolic stockings were applied. HRT was stopped. The initial ECG showed a tachycardia with tall $\mathrm{P}$ waves and low voltage QRS complexes (fig 1). Since atrial tachycardia was considered in the differential diagnosis, adenosine was given, which temporarily slowed the $\mathrm{P}$ wave rate, altered the $\mathrm{P}$ wave morphology, and produced intermittent atrioventricular block (fig 2). Possible ECG

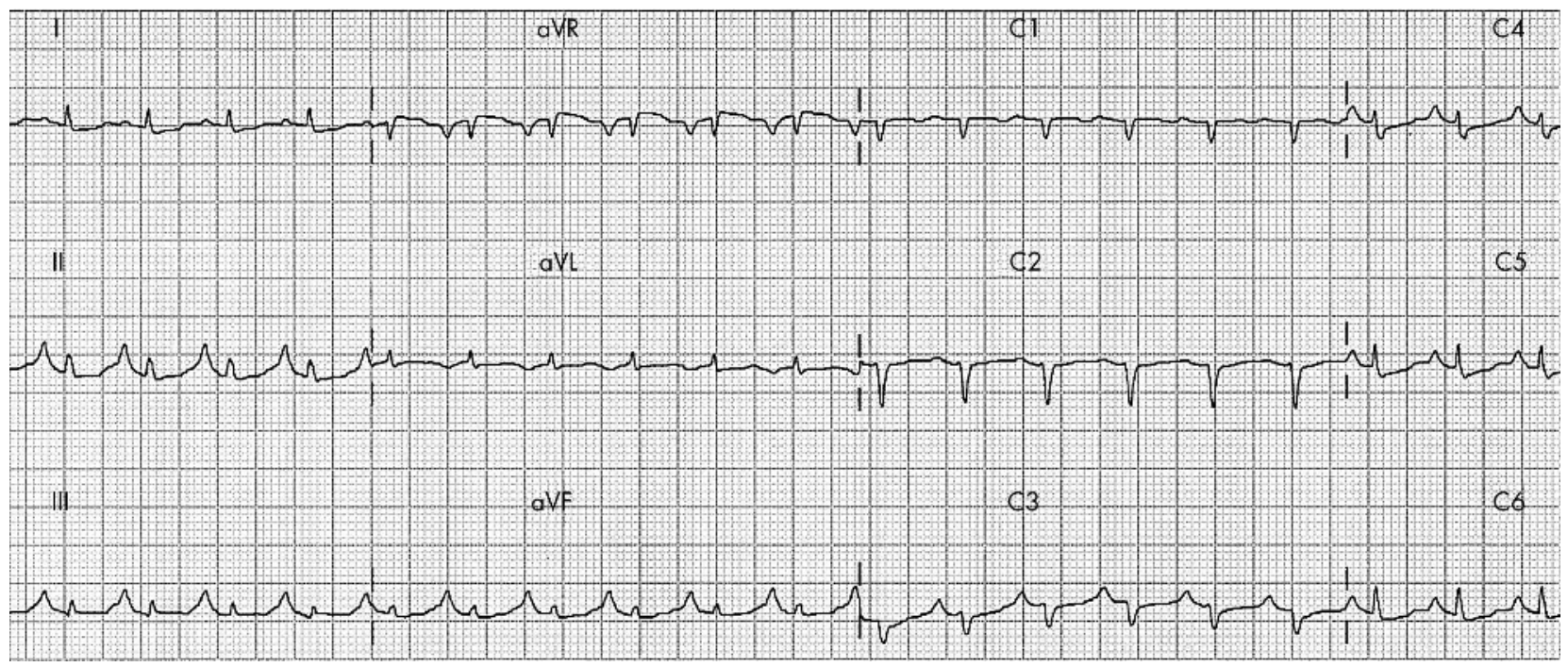

Figure 1 Initial ECG at presentation. 

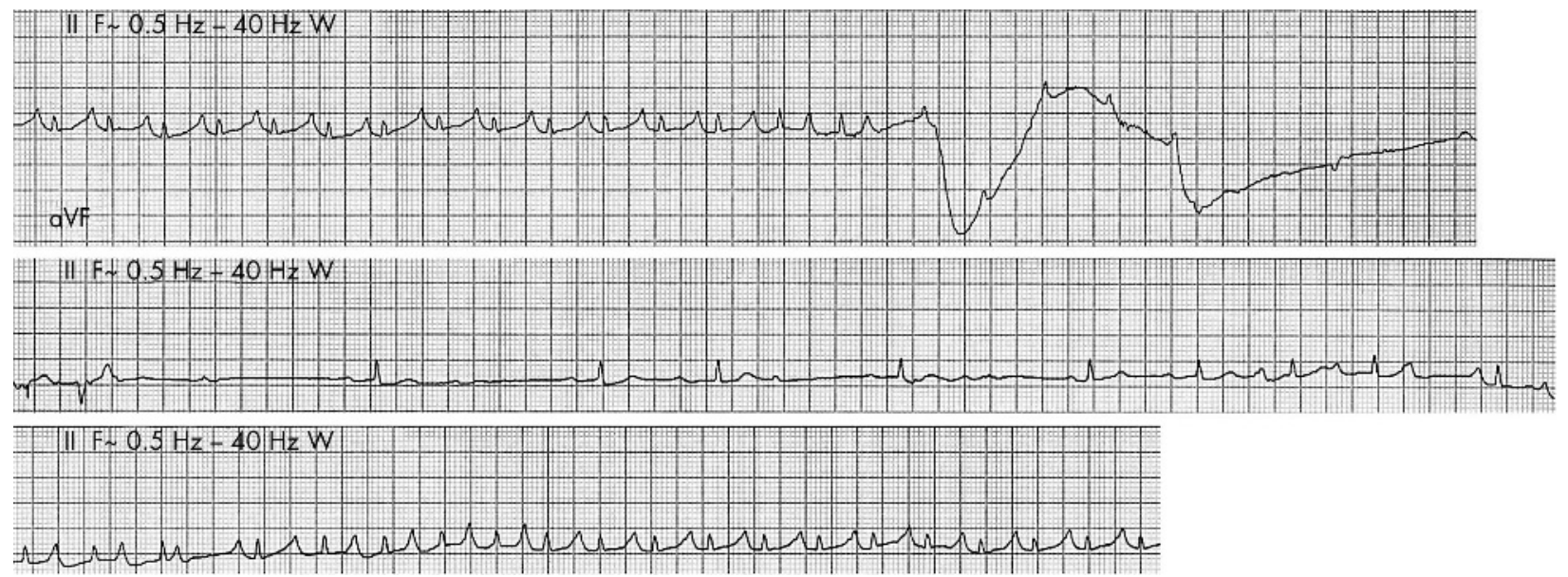

Figure 2 Rhythm during adenosine administration.

diagnoses were sinus tachycardia with $\mathrm{P}$ pulmonale and atrial tachycardia. Flecainide was tried with no effect and was discontinued.

The following day, results showed D dimers $5459 \mathrm{ng} / \mathrm{ml}$ and troponin I $1.3 \mu \mathrm{g} / \mathrm{l}$. Ventilation/perfusion scanning showed extensive perfusion defects throughout both lungs with a high likelihood of emboli. Subsequent spiral computed tomography angiography showed massive bilateral clots in the main trunk of the pulmonary arteries and no evidence of deep vein thrombosis. The patient was thrombolysed with alteplase (100 mg over two hours), enoxaparin was continued at a therapeutic dose for a further week, and warfarin was commenced.

Serial ECGs showed a gradual reduction in the $\mathrm{P}$ wave amplitude (fig 3) and resolution of tachycardia. Echocardiography after thrombolysis and anticoagulation showed that right and left ventricular dimensions and function were within normal limits and a suggestion of
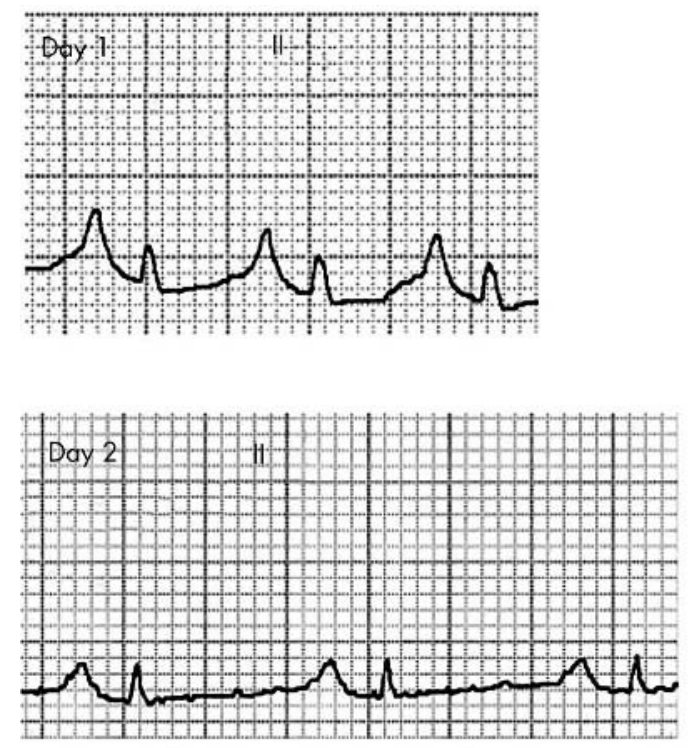
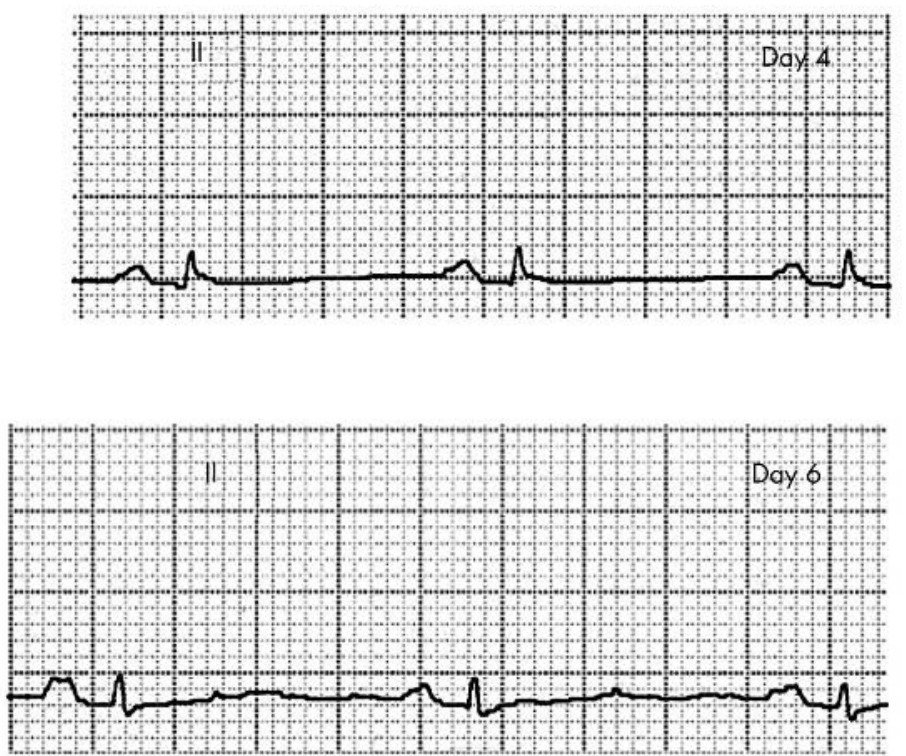
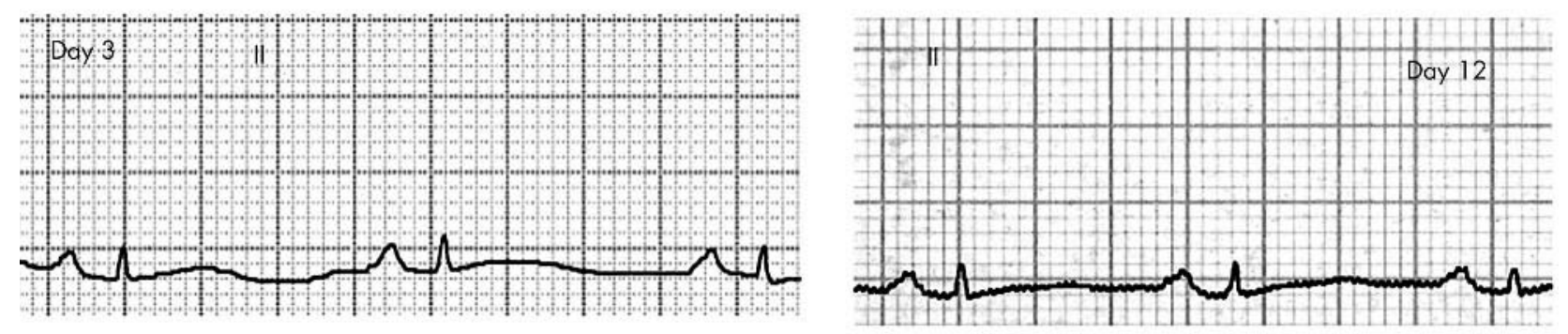

Figure 3 ECG changes in lead II over the course of admission. 
thrombus at the junction of the main and right pulmonary arteries.

The patient was discharged and prescribed warfarin for six months in the first instance, aiming for an international normalised ratio of $2-3$, and thyroxine $25 \mu \mathrm{g}$ daily in view of her newly diagnosed hypothyroidism, with arrangements to see her in the outpatient clinic.

\section{DISCUSSION}

PE remains an important clinical problem with a high mortality rate. ${ }^{1}$ The most common symptoms at the time of diagnosis are dyspnoea (82\%) and chest pain (49\%). The risk factors are well documented and HRT is associated with a two- to fourfold increased risk of idiopathic venous thrombosis, compared with women not taking HRT. ${ }^{2-4}$

The ECG is abnormal in over $70 \%$ of patients with PE. ${ }^{5}$ ECG findings in PE may include sinus tachycardia, dominant $\mathrm{R}$ wave in lead $\mathrm{Vl}$, right bundle branch block, right axis deviation (deep $\mathrm{S}$ wave in lead I), Q wave and inverted $\mathrm{T}$ wave in lead III (when combined with a deep $\mathrm{S}$ wave in lead I, this gives the $S_{I} Q_{I I I} T_{I I I}$ pattern suggestive of right ventricular strain), $\mathrm{T}$ wave inversion in leads $\mathrm{Vl}$ to $\mathrm{V} 4$, $\mathrm{P}$ pulmonale, supraventricular arrhythmias, and clockwise rotation (persistent S wave in lead V6). The 12 lead ECG provides important prognostic information in patients with PE. For example, the presence of premature ventricular extrasystoles, atrial fibrillation, and low voltage QRS complexes (as in this case) are associated with increased 30 day mortality. ${ }^{6}$

With the advantage of hindsight, we can state that this patient probably had a sinus tachycardia with $\mathrm{P}$ pulmonale, especially in view of the gradual reduction in $\mathrm{P}$ wave amplitude. By looking solely at the initial ECG, and without electrophysiological studies, it is difficult to differentiate this from atrial tachycardia, which may occur in PE and produce similar $\mathrm{P}$ wave morphology. However, the response to adenosine and lack of response to flecainide do not support a diagnosis of atrial tachycardia.

The gradual reduction in $\mathrm{P}$ wave amplitude may reflect a reduction in right atrial strain after treatment. Interestingly, Asad and colleagues ${ }^{7}$ observed, in patients with acute exacerbations of chronic obstructive pulmonary disease, a decrease in P wave amplitude between the emergency room and subsequent ward ECGs.

ECG abnormalities, such as the $\mathrm{S}_{\mathrm{I}} \mathrm{Q}_{\text {III }} \mathrm{T}_{\text {III }}$ pattern, right bundle branch block, and anterior $\mathrm{T}$ wave inversion, have been observed to return to normal after treatment for PE. ${ }^{8-10}$ Ferrari and colleagues ${ }^{10}$ observed that anterior $\mathrm{T}$ wave inversion was present in $85 \%$ of cases of massive PE and $19 \%$ of cases of non-massive PE, and that its reversibility before the 60th day pointed to a good outcome. They also found that ECG findings of sinus tachycardia and pulmonary $\mathrm{P}$ wave as determined by amplitude of $\geqslant 0.25 \mathrm{mV}$ in lead II (both present in this case) each had $100 \%$ specificity and $100 \%$ positive predictive value in assessing the severity of PE but had poor sensitivity and negative predictive value.

It is notable that troponin I was increased in this patient, as troponin I has been shown to be of value in risk stratification and short term prognostication in acute PE. ${ }^{11}$ Pruszczyk and colleagues ${ }^{12}$ found that patients with an increased troponin concentration were 20 times more likely than patients with normal troponin concentrations to die or require an escalation of treatment due to a complicated hospitalisation. ${ }^{12}$
Thrombolytics are usually reserved for the treatment of acute massive embolism with haemodynamic instability. ${ }^{13}$ However, echocardiographic evidence of right ventricular dysfunction can identify patients who, despite initial haemodynamic stability, develop cardiogenic shock and are at increased risk of death. ${ }^{14}$ Furthermore, the management strategies and prognosis of pulmonary embolism-3 trial showed that alteplase prevented the need for escalation of treatment (such as catecholamine infusion, intubation, cardiopulmonary resuscitation, and surgical embolectomy) due to clinical deterioration in patients with acute PE and pulmonary hypertension or right ventricular dysfunction but without arterial hypotension. ${ }^{15}$ On this basis, some consider extending the indications for thrombolysis.

\section{Authors' affiliations}

A S H Cheng, Department of Cardiology, Hammersmith Hospital, London, UK

A Money-Kyrle, Departments of Cardiology and General Medicine, Stoke Mandeville Hospital, Aylesbury, Buckinghamshire, UK

Competing interests: None

Correspondence to: Dr Adrian S H Cheng, 122 Meadvale Road, Ealing, London W5 1LR, UK; adrianc@doctors.org.uk

Accepted 8 November 2004

\section{REFERENCES}

1 Goldhaber SZ, Visani L, De Rosa M. Acute pulmonary embolism: clinical outcomes in the international cooperative pulmonary embolism registry (ICOPER). Lancet 1999;353:1386-9.

2 Anderson FA Jr, Spencer HA. Risk factors for venous thromboembolism. Circulation 2003;107:19-16.

3 Daly E, Vessey MP, Hawkins MM, et al. Risk of venous thromboembolism in users of hormone replacement therapy. Lancet 1996;348:977-80.

4 Nelson HD, Humphrey LL, Nygren P, et al. Postmenopausal hormone replacement therapy: scientific review. JAMA 2002;288:872-81.

5 Stein PD, Terrin ML, Hales CA, et al. Clinical, laboratory, roentgenographic, and electrocardiographic findings in patients with acute pulmonary embolism and no pre-existing cardiac or pulmonary disease. Chest 1991:100:598-603.

6 Sallach JA, Sallach SM, Thomas JD, et al. Prognostic value of electrocardiographic abnormalities in patients with acute pulmonary embolism. Chest 2003;124:S239.

7 Asad N, Johnson VMP, Spodick DH. Acute right atrial strain: regression in normal as well as abnormal $\mathrm{P}$-wave amplitudes with treatment of obstructive pulmonary disease. Chest 2003;124:560-4.

8 McGinn S, White PD. Acute cor pulmonale resulting from pulmonary embolism. JAMA 1935;104:1473-80.

9 Durant TM, Ginsburg IVY, Roesler H, et al. Transient bundle branch block and other electrocardiographic changes in pulmonary embolism. Am Heart $J$ 1939:17:423-30.

10 Ferrari E, Imbert A, Chevalier T, et al. The ECG in pulmonary embolism: predictive value of negative $T$ waves in precordial leads: 80 case reports. Chest 1997; 111:537-43.

11 Konstantinides S, Geibel A, Olschewski M, et al. Importance of cardiac troponins I and $T$ in risk stratification of patients with acute pulmonary embolism. Circulation 2002;106:1263-8.

12 Pruszczyk P, Bochowicz A, Torbicki A, et al. Cardiac troponin T monitoring identifies high-risk group of normotensive patients with acute pulmonary embolism. Chest 2003;123:1947-52.

13 Hyers TM, Agnelli G, Hull RD, et al. Antithrombotic therapy for venous thromboembolic disease. Chest 2001;119:176S-93S

14 Grifoni S, Olivotto I, Cecchini P, et al. Short-term clinical outcome of patients with acute pulmonary embolism, normal blood pressure, and echocardiographic right ventricular dysfunction. Circulation 2000;101:2817-22.

15 Konstantinides S, Geibel A, Heusel G, et al. for the Management Strategies and Prognosis of Pulmonary Embolism-3 Trial Investigators. Heparin plus alteplase compared with heparin alone in patients with submassive pulmonary embolism. N Engl J Med 2002;347:1143-50. 